\title{
Clínica psicológica fenomenológica existencial como espaço de resgate do sonho'
}

\author{
Existential phenomenological psychological clinic as a possibility of rescue of dreams
}

\author{
Rafael Auler de Almeida Prado ${ }^{[a]}$, Marcus Tulio Caldas ${ }^{[b]}$, Carmem Lúcia Brito Tavares Barreto ${ }^{[c]}$
}

\footnotetext{
${ }^{[a]}$ Doutorando em Psicologia Clínica pela Universidade Católica de Pernambuco (UNICAP), Recife, PE - Brasil, e-mail: rafaelpradoauler@gmail. com

${ }^{[b]}$ Doutor em Psicologia pela Universidade de DeustoEspanha, professor da graduação e pós-graduação do curso de Psicologia da Universidade Católica de Pernambuco (UNICAP), Recife, PE - Brasil, e-mail: marcus_ tulio@uol.com.br

${ }^{[c]}$ Doutora em Psicologia Clínica pela Universidade de São Paulo (USP), professora do Programa de Pós-Graduação em Psicologia Clínica da Universidade Católica de Pernambuco (UNICAP), coordenadora do Laboratório em Psicologia Clínica Fenomenológica ExistencialLACLIFE, Recife, PE - Brasil, e-mail: carmemluciabarreto@ hotmail.com
}

Recebido: 19/09/2010 Received: 09/19/2010

Aprovado: 03/11/2010 Approved: 11/03/2010

\section{Resumo}

A sociedade contemporânea é marcada por uma crise de sentido. Vivemos de forma individualista e competitiva, sem nos preocuparmos uns com os outros e deixando de lado, muitas vezes, o que mais profundamente nos diz respeito: nossa intimidade. Acreditamos que, em boa parte, isso se deva ao lugar que a técnica moderna vem ocupando na vida das pessoas. Sendo a técnica o motor da sociedade, nossa capacidade de sonhar que a ela não se enquadra e que para esta não tem serventia, vem sendo desprezada. Procuramos mostrar com este artigo, por meio de reflexão teórica e pesquisa bibliográfica, a importância da nossa capacidade de sonhar como forma de nos lançarmos para além dos limites que a técnica nos impõe, ou seja, em direção ao outro, a nós mesmos e à nossa felicidade. As modalidades do sonhar aqui abordadas são o desejo, o devaneio poético e a imaginação poética. Nesta direção, apontamos a importância do sonho na prática da clínica fenomenológica existencial.

Palavras-chave: Capacidade de sonhar. Psicologia clínica fenomenológica existencial. Técnica moderna. Sonho como desejo. Sonho como imaginação poética.

\begin{abstract}
Contemporary society has been achieved by a crisis in meaning. We have lived in an individualistic and competitive way without caring about each other and, many times, leaving out what most deeply concerns us: our intimacy. We believe that, in large part, this is due to the importance that modern technique has gained into people's lives. Modern technique, in our conception, is the engine of society. Our capacity to dream, in this context, has been neglected, because it's not considered important or useful. Based on bibliographical research and theoretical thinking we intend to show through this article the importance of our capacity to dream as a way to put ourselves beyond the limits that technique imposes on us, that is, toward each other, toward ourselves and toward our happiness. The modalities of dream discussed here are
\end{abstract}

1 Agradecemos ao Fundo de Amparo à Ciência e à Tecnologia do Estado de Pernambuco (Facepe) pela concessão de bolsa de Doutorado, que nos permitiu a realização do presente artigo. 
desire, poetic reverie and poetic imagination. In this direction, we point out the importance of the dream to clinical practice of existential phenomenology.

Keywords: Capacity to dream. Existential phenomenological psychological clinic. Modern technique. Dream as wishing. Dream as poetic imagination.

\section{Introdução}

Vivemos hoje, numa época em que, cada vez mais se acentua o individualismo, a competição e a sensação de vazio. Diante de um mundo movido pela produção e pelo consumo, muitas de nossas possibilidades humanas de cuidado com o outro, conosco e com nosso mundo ficaram restritas. A partir do sentido da técnica moderna e do ritmo que esta impõe, também restringimos nossos sonhos a sonhos de consumo e passamos a atribuir suas realizações ao nosso poder aquisitivo. Nossos sonhos e nossas realizações são da ordem de viagens, compra de carros, casa, roupas. 0 poder de realização é medido pelo quanto nosso dinheiro pode comprar. 0 sonho como devaneio, como um "se demorar imaginativamente" em algum aspecto fundamental de nosso mundo, como momento de construção e desvelamento de um mundo que vivenciamos é entendido como mera perda de tempo. Só tem valor o tempo de trabalho gasto em atividades práticas que, efetivamente, podem aumentar nosso poder de aquisição. A filosofia, a literatura, a arte e a poesia perdem espaço no mundo contemporâneo.

Aliamos a essa contribuição, uma reflexão de cunho heideggeriano, buscando mostrar como a técnica moderna foi se estabelecendo como modo hegemônico de pensar e de ser por toda a sociedade. A crítica heideggeriana vê a consolidação da técnica pelo viés da questão do ser, ou seja, pela história do modo como o ser vem sendo pensado pelo Ocidente. Essa consolidação da técnica traz como um de seus desdobramentos a limitação de nossa capacidade de sonhar.

0 estudo acerca da imaginação poética de Gaston Bachelard apresenta-se como uma tentativa de resgatar essa dimensão humana, já que, numa reflexão filosófica, retoma a poética, repensa o lugar da literatura e da arte na vida do homem, trazendo a imaginação como propriedade criativa humana fundamental e não como representação de um dado recordado, como é tratada pelo nosso pensamento contemporâneo.

Assim, ressaltamos alguns aspectos do sonho que não estão sendo considerados nos dias atuais. Por fim, apontaremos algumas possibilidades de se considerar o sonho na clínica psicológica. De acordo com a sequência das temáticas apresentadas anteriormente, dividimos o artigo em três itens: o primeiro apresenta a técnica moderna a partir da crítica heideggeriana; o segundo enfoca nossa capacidade e nossas possibilidades de sonhar, ressaltando o sonho como devaneio numa perspectiva bachelardiana; e o terceiro (considerações finais) apresenta uma reflexão a respeito de alguns desdobramentos do sonhar na prática psicológica, numa perspectiva fenomenológica existencial.

\section{A questão da técnica moderna e o desenraizamento do homem a partir da dimensão ontológica, numa perspectiva Heideggeriana}

Heidegger interpreta a crise da modernidade a partir da questão do ser. Para ele, o cerne da crise do homem moderno, "[...] não está nem no plano da teoria nem da ação - mas no plano do ser. E o ser só pode ser pensado" (Michelazzo, 2000, p. 132). Por isso, começamos o item apresentando alguns aspectos do pensamento heideggeriano acerca do ser, necessários para orientar nossas reflexões. Veremos de que forma as análises de Heidegger e de autores que nele apoiam suas reflexões podem ampliar as possibilidades de intervenção na clínica psicológica. Certamente, essa modalidade de pensamento não aponta saídas práticas, imediatas e concretas, mas, abre para a possibilidade de dizer sim e não à técnica como postura possível diante dela. Tal perspectiva, Heidegger chama de "serenidade".

Tomamos Michelazzo (2000) como referência, pois o autor, numa perspectiva heideggeriana, reflete a respeito da contemporaneidade a partir de uma relação entre a ontologia fundamental e a prática profissional 
do psicólogo, ressaltando que os problemas e sofrimentos psicológicos apresentam-se, ao mesmo tempo, pessoais e típicos da modernidade. A ontologia (estudo do ser) que Heidegger propõe é considerada "fundamental" pelo autor no sentido que pensa o ser a partir de seu fundamento, ou seja, existindo na sua impermanência e na sua mutabilidade.

Heidegger $(2001,2008)$, no início da trajetória de seu pensamento, pensou o ser a partir do tempo, passando depois para uma análise da existência humana, Daseinsanalyse. Apontou que a Metafísica operou o esquecimento do sentido do ser, ao reduzir as possibilidades do pensamento à superfície da adequação entre a inteligência e o real. Ressaltou, ainda, a necessidade de considerar o desvelamento do ser no aparecer dos entes particulares, não se limitando ao contorno de nenhuma determinação particular. Nessa direção, a ênfase é dada ao modo de pensar fundado na aletheia, uma experiência mais ampla que a da razão, mais próxima ao poetar, que é a experiência da relação com a própria abertura do ser e de por ela ser interpelado.

Nessa direção, reflete também acerca do tempo compreendido na dimensão existencial do que passa, do que se move, do que nunca permanece o mesmo. Critica a hegemonia que o pensamento metafísico pode atingir, a ponto de apenas considerar verdadeiro o que é permanente e constante, passível de mensuração e cálculo, permitindo previsão e controle. 0 método metafísico é extremamente válido e útil na produção de conhecimento e de tecnologia, no entanto é limitado para se fazer uma análise da existência humana, posto que ela tem como um de seus fundamentos o tempo, imutável e inconstante. Uma sociedade que pensa exclusivamente a partir de um modo metafísico restringe também seu modo de ser ao modo da previsibilidade e do controle e se fecha para a novidade e o imprevisível. 0 modo como as pessoas se relacionam umas com as outras e com o mundo são marcados por uma rotina rígida, racionalmente estabelecida, em que cada um se torna uma engrenagem de uma grande máquina social.

A busca pelo que é constante, permanente, sobre o qual podemos formar uma ideia é apenas uma face do real que podemos apreender numa reflexão intelectual. Essa é uma solução encontrada para anular a constante impermanência e mutabilidade do real. É o modo como a técnica toma o ser.
O ser concebido como "presença constante" diz respeito apenas a uma de suas dimensões, a do verbo ser no presente - "é", como algo subsistente, "simplesmente dado", que pode ser observado, calculado e teorizado. Essa dimensão do ser não é de forma alguma equivocada, mas parcial e possível, a partir de uma elaboração intelectual secundária do sentido fundamental e originário do tempo. Por isso, Heidegger busca uma compreensão do tempo a partir de seu "sentido originário" (Michelazzo, 2003), que diz respeito à origem do tempo, o que é o tempo, a partir do qual outros sentidos de tempo se tornaram possíveis, assim como a concepção que se tornou a corrente, quase hegemônica, como sucessão quantitativamente mensurável de agoras (tempo do relógio e do calendário).

Na trajetória do pensamento de Heidegger que o leva à análise do ser-aí, o filósofo aponta que o ser não é simplesmente dado ao homem de forma pronta, uniforme, ele se constitui no mundo-com-os-outros, numa dimensão espacial e temporal. Nessa direção, tempo é compreendido como destinação. 0 ser se destina a ser pensado e vivido pela sociedade a partir de sua história e significatividade do mundo, em que cada coisa, ação, ideia se insere, recebendo seu "sentido". Assim, o ser se resgata por um pensar que não se sedimenta cientificamente, podendo ser trazido à "luz" por um esforço de pensar que, ao desvelar a existência, deixa-a em liberdade para "apropriar-se".

Tendo homem e mundo relações, implicações e responsabilidades tão estreitas, é impossível pensá-los e tratá-los separadamente. Por isso, Michelazzo (2000) critica uma intervenção clínica psicológica que separa a serenidade do consultório e a "loucura" do mundo fora dele. Para o autor, a clínica deve acolher o paciente que sofre com as implicações da crise contemporânea, permitindo que ele entenda que o problema não é somente dele, paciente, mas que o mundo também está doente. A doença é o esquecimento de um sentido. A técnica, levada ao extremo, tornou as pessoas competitivas e individualistas. 0 compromisso com os outros e com o mundo foi se anulando. É diante deste mundo que o paciente tem que se posicionar. Ele não é nem o culpado nem vítima do mundo. A partir dessa compreensão, o paciente poderá se apropriar mais de seu modo próprio de ser. A clínica pode, neste sentido, intervir, ajudando o paciente a se situar diante desse mundo técnico. 
O homem, na perspectiva heideggeriana, é compreendido como Dasein (ser-no-mundo ou ser-aí). Homem e mundo são coconstitutivos e co-originários, concepção que difere das representações psíquicas que separam o homem e o mundo nas qualidades de sujeito e de objeto. Assim, para a $d a-$ seinsanalyse não existe um aparelho psíquico ou um mecanismo causal que determine o comportamento humano. $\mathrm{O}$ homem, ao ser compreendido como ser-no-mundo, deve refletir a determinação das estruturas existenciais do Dasein. Sob este ponto de vista, o existencial (modo de ser do Dasein), - que fornece o fio condutor para esta análise, - é a compreensão (Verstehen). 0 pressuposto de toda compreensão é uma certa "pré-compreensão", um certo horizonte preliminar, aberto e acessível, que possibilita a liberdade da compreensão. A compreensão mantém num estado de abertura preliminar as relações e referências que dão significatividade ao mundo.

Para Heidegger (2008), o mundo não dá ao homem o mesmo acolhimento que dá aos outros entes. Os entes intramundanos têm lugar determinado no mundo como destinação de sua vigência. Uma pedra se destina a ser pedra, uma flor a ser flor e um animal, a ser um animal. 0 homem tem, no mundo, a experiência originária de inospitalidade, precisando construir sua referência do mundo, dos outros e de si uma dimensão de significatividade que, paradoxalmente, não é estabelecida por cada indivíduo em um determinado tempo e lugar. Essa dimensão nos antecede, é obra de "todos", é algo pré-dado e que nos chega por "doação". Tal significatividade é apreendida no cotidiano como algo natural, como valores e conceitos já dados, e promovem a experiência de segurança, que "protege" o homem de defrontar-se com o "vazio", onde precisaria se reinventar. Tal situação torna evidente a "perda do ser" como também a possibilidade de resgatá-lo. Por conta dessa condição de estar-no-mundo, o homem precisa viver a "tragédia" da existência, assumindo a dor de viver como possibilidade libertadora do seu acontecer como humano.

Após esta breve reflexão sobre a questão do ser, vamos percorrer o caminho encontrado por Heidegger para a construção do seu modo de pensar, fazendo um "retorno às origens" pela trilha dos pré-socráticos e continuando pelo pensamento platônico - marco da origem do pensamento moderno. Heidegger (2008) aproxima sua compreensão de ser ao ser da phýsys, por se propor a pensá-lo como impermanente e transitório.
O pensamento da phýsys, anterior a Platão, fazia-se como espanto, como um olhar que se maravilha com o que vê. Phýsys diz respeito a brotar, conservar, permanecer e morrer. Tudo que existe está em tensão (Heráclito, 1999). Tudo está no fluxo da impermanência e da transitoriedade. A "perene tensão" (Michelazzo, 2000) era celebrada na tragédia, no teatro e na poesia grega.

Embora a "angústia originária" seja ontológica, a consciência desta poderia ter surgido da evidência de nossa impermanência e de nossa transitoriedade, por meio do pensamento da phýsis (Michelazzo, 2000). 0 pensamento metafísico ocidental inaugurado por Platão surgiu como tentativa de livrar o homem de sentir angústia diante da decadência, da deterioração e da morte corporais, além da insegurança em relação à verdade da existência das coisas (transmutação), ao buscar uma situação de domínio e controle. Assim, a essência de algo se dissocia de sua aparência, compreendida como eminentemente impermanente e transitória, e vincula-se à permanência e constância de algo.

A perspectiva que domina o pensamento ocidental desde Platão caracteriza-se pela busca da permanência. Por isso privilegia-se quase que exclusivamente o traço teórico e abstrato do pensamento como fonte de verdade. Critelli (1996) identifica que a coincidência entre "ser e substância" e "verdade e representação" é um pressuposto oriundo dos pensamentos de Platão e Aristóteles. Platão (1999) considerava que havia um mundo ideal e não aparente, de que só o espírito poderia se recordar (processo chamado de reminiscência), pois já teria estado lá antes de vir ao mundo sensível. 0 ser, para Platão, é imaterial e não sensível; e o ente é material e sensível.

Apesar de discípulo de Platão, Aristóteles (1969) considerava que o "inaparente do ser", seu conceito, não está em um mundo à parte do mundo aparente, sensível, mas no mundo sensível mesmo. Seu acesso pode ser realizado pelo intelecto. Aristóteles consolida, assim, a perspectiva platônica da necessidade de um método para fazer conhecimento. As ideias passaram a ser produzidas pelo pensamento que seguia procedimentos lógicos. A partir de Aristóteles, passou-se a consolidar a ideia de "coisa em si" e "consciência em si", duas instâncias que existem e se sustentam separadamente. Descartes reafirma a separação de "coisa em si" e "consciência em si" na noção de sujeito e objeto. Sobre essa noção se apoiam as ciências naturais. Observação, mensuração, classificação e verificabilidade tornam-se os 
procedimentos de investigação que permitem certificação de algo, segundo o modelo metafísico do ente, que considera que só se tem certeza de algo, se esse algo tiver patência e tangibilidade.

Mas é a partir da modernidade que esse caráter de dominação presente neste pensamento, começa a ganhar força gigantesca. A partir de então tem que estar na condição de claro e distinto, porque o sujeito procura sempre determiná-lo por meio de uma representação que persegue a certeza e o cálculo. E essa marcha chega até nós, cada vez mais poderosa e dominadora (Michelazzo, 2000, p. 139).

Após esse percurso que preparou o aparecimento da ciência e da técnica, chegamos a nossa época, séculos XX e XXI, profundamente marcada por domínio imenso da técnica, "a época da técnica planetária” (Michelazzo, 2000, p. 132). 0 desenvolvimento técnico e industrial da contemporaneidade só foi possível a partir da constituição de um sujeito que representa e calcula seus objetos. Assim surgem máquinas e automação dos serviços.

O sentido original de técnica, segundo Heidegger (2001), é technikós, referente à habilidade do artista, do artesão. Téchne, da mesma raiz etimológica, diz respeito a trazer algo de seu ocultamento para seu desocultamento. Referia-se à arte e à poesia. A técnica moderna, segundo Heidegger, também é um modo de desvelamento do mundo, que ele chama de "provocação". 0 mundo provoca o homem a desvelá-lo como recurso para produção de riqueza e para estabelecimento de poder, por meio do controle e do cálculo. Foi a partir do capitalismo que o fenômeno da técnica moderna se consolidou com mais força. As sociedades industriais surgiram da técnica e do capitalismo.

No mundo contemporâneo, o homem não consegue mais criar raízes com as coisas, com as pessoas e os lugares, pois tudo é transitivo, é equivalente, tem o mesmo valor, o financeiro-comercial. Nenhuma organização como o Estado, um grupo religioso ou um movimento civil pode dar conta da situação contemporânea. A técnica pode levar o homem a se restringir à possibilidade de ser impropriamente. A tecnologia, além de controlar o real, cria uma outra realidade, a virtual, mais sedutora como sociedade que a "real".

Nesse panorama em que o ser ficou restrito às modalidades ônticas e entificadas, dimensões do ser humano foram deixadas de ser pensadas, valorizadas e vividas. Dominada por tal perspectiva técnica, nossa imaginação, nossa capacidade de sonhar com olhos abertos, ficaram reduzidas a um epifenômeno da memória. 0 sonhador é, na maioria das vezes, considerado um divagador, e o ato de devanear é tratado como uma divagação, uma improdutividade. A falta de lugar do sonho em nossa sociedade torna as pessoas mais distantes de si e dos outros, e menos felizes.

Com o intuito de mostrar um possível lugar do resgate do sonho na contemporaneidade, apresentamos nos itens subsequentes como o sonhar no sentido de desejo, na compreensão de Pompéia \& Sapienza (2004); e de devaneio e "imaginação criadora" na perspectiva de Bachelard (2001) tem papel fundamental na nossa existência, dimensão não privilegiada pela civilização ocidental moderna. Veremos que o sonho alimenta nossa intimidade conosco, com o mundo e com os outros, dando-lhes sentido e nitidez.

\section{A dimensão do sonho}

De acordo com o pensamento de Heidegger, concebo a experiência como o modo específico de ser do homem. É diferente do ser das coisas, do ser dos animais. Nesse sentido mais rigoroso, só o homem existe.

E o que é próprio do ser do homem? Para apontar essa peculiaridade, vou dizer que o homem é um sonhador. Num certo sentido, o que chamo de existência é a condição de sonhador do homem.

Diferentemente dos animais, o homem é movido por aquilo que ainda não é. O que ainda não é é expectativa, projeto, imagem, sonho; mesmo que nunca venha a ser, que permaneça como pura possibilidade, esse ainda não é é exatamente o que permite a possibilidade de ser (se já fosse não seria possibilidade). A força maior dessa perspectiva de futuro pode vir desse ainda não (Pompéia \& Sapienza, 2004, p. 18)

No fragmento acima, Pompéia nos aponta que o sonhar está vinculado a nossa exclusiva e caracterizadora condição humana de estarmos voltados para o futuro que está em aberto, que ainda não se configurou. Neste sentido, sonhar é uma condição humana fundamental, aberta enquanto possibilidade, mesmo que o homem viva uma relação exclusivamente técnica consigo, com o mundo e com os outros. Se a capacidade de sonhar é inerente à condição humana, de modo que, para existirmos, necessariamente sonhamos, por que estamos fazendo uma reflexão que pensa no resgate do sonho? 
A dimensão do sonho, na sociedade contemporânea - que vive em função da técnica - é vivenciada apenas na sua modalidade de projeto racionalmente estabelecido, logicamente construído a partir do abstrato, do intelecto. Num mundo em que a experiência vivida e seu sentido não ocupam lugar de importância, nosso coração continua nos acenando, convidando-nos a viver aquilo que tem significado especial para nós. No entanto, a prudência, a tendência a valorizar o que é produtivo (do ponto de vista de riqueza material) falam mais alto e passamos a achar que nossos sonhos são meros pensamentos irreais ou ingênuos. Assim nos distanciamos dos nossos sonhos, não assumindo a possibilidade de que pertencem a nossa existência e ao nosso modo de ser-no-mundo.

Considerando tal contexto, o sonho humano será enfocado sob dois diferentes aspectos. Seguindo uma reflexão de Pompéia e Sapienza (2004), pensaremos primeiramente o sonho como desejo mobilizador de vida. Veremos como nossos sonhos têm importância, como eles são nossa força de ser. Nossos sonhos têm um ciclo. Eles nascem, permanecem por um tempo e morrem. Pompéia mostra como, às vezes, deixamos de sonhar pelo fato de um determinado sonho não ter se realizado e continuarmos presos a ele, como se só aquele sonho fosse importante. É mister também deixar os sonhos morrerem para que recuperemos nossa capacidade de sonhar e sonhemos de novo.

Posteriormente, enfocamos Bachelard, que, nas suas obras acerca da imaginação e o devaneio poético, fala de um sonhar acordado, mas não está diretamente ligado a um desejo ou voltado para a realização de um desejo. A modalidade de sonho de que trata Bachelard é o devaneio que nos ajuda a nos situarmos no mundo, a significá-lo e a dar-lhe sentido. 0 devaneio cria um mundo e, expresso em linguagem escrita, ele se torna imagem poética. Em outras palavras, é em linguagem poética que o devaneio se expressa.

\section{0 sonho como desejo}

O sonho compreendido como desejo são nossas aspirações e apontam para nossas possibilidades de estar-no-mundo. Nossos sonhos, neste âmbito, são o que mais encarecidamente desejamos, o que desejamos de coração. Por nos serem tão caros, tão especiais, tão íntimos, nossos sonhos nos mobilizam no mundo, nos revelam o sentido para o que fazemos. Por isso, muitas vezes nos decepcionamos diante da impossibilidade de realizarmos determinado sonho, concluímos que são mera irrealidade e não têm importância. Um mundo compreendido tecnicamente não favorece em absoluto o sentimento de confiança nos sonhos e na capacidade de sonhar. Assim, podemos nos tornar desesperançosos ou vivermos a partir da produtividade e da capacidade de consumo conquistada. Um viver de pressa, competição e acúmulo se instaura a partir da técnica.

Ouvir nossos sonhos é importante para podermos nos colocar no mundo a partir de nosso modo próprio de ser. Nossos sonhos nos convidam a realizar aquilo pelo que somos tocados. Nem sempre podemos realizar o que desejamos, mas não desejamos sempre a mesma coisa. Segundo Pompéia e Sapienza (2004), os sonhos da maioria de nós todos têm em comum o desejo de sermos felizes com os outros. Nossos sonhos podem também ser compreendidos como um convite para sermos felizes com os outros de uma determinada maneira e em um dado momento, numa certa situação. No entanto muitas vezes não conseguimos deixar um sonho morrer ou nos lamentamos por sonhos que não puderam ser realizados como se só eles fossem importantes, e a sua impossibilidade de realização passasse a ser compreendida como a impossibilidade de realização de sonhos, de um modo geral.

Ainda segundo Pompéia e Sapienza, a morte de um sonho abre espaço para outro sonho nascer e vivermos a partir deste novo sonho, por mais um tempo. Nossa capacidade de sonhar não se perde na morte de um sonho. $\mathrm{O}$ autor referido traz a imagem de uma árvore, que se nutre de suas próprias folhas secas que caem no solo onde ela está enraizada, para expressar o modo como nossos sonhos novos se alimentam de nossos sonhos velhos. É no sonho de ser feliz com os outros que me recupero como sonhador. Ser feliz é o que mobiliza cada sonho. Cada vez, "ser feliz" vai acenar de um certo modo para o sonhador.

O sonho também tem um caráter de solidão. É na nossa solidão que conseguimos nos encontrar, e tal situação nos possibilita ver com nitidez como estamos implicados no mundo com os outros, como o mundo nos toca e em qual direção ele nos acena. "Toda vez que temos um sonho muito precioso, muito curtido, no qual escrevemos muitas histórias, e esse sonho morre, nós nos sentimos solitários" 
(Pompéia \& Sapienza, 2004, p. 39). Na morte de um sonho, uma parte nossa muita íntima, muito minha, morre. Essa parte nossa não só não pertence mais ao mundo, como só pode pertencer a nós como uma coisa morta, como uma lembrança lamentativa do que poderia ter sido. Se não conseguimos deixar um sonho morrer, nos impedimos de abrir espaço para novos sonhos e nossa felicidade se perde de vista.

Não podemos perder de vista que "[...] são nossos sonhos que nos fazem sensíveis, que nos abrem para o cuidado dos outros, das coisas e até de nós mesmos" (Pompéia \& Sapienza, 2004, p. 40). Se perdermos isso de vista, perdemos o que temos de mais humano. Acreditamos que Pompéia afirma, na citação inicial deste item, que o homem é um sonhador, porque só o homem tem a capacidade de buscar sua felicidade e buscá-la a partir de seu modo próprio de ser, que é proporcionado pelos sonhos. A técnica padroniza o sonho do homem a sonhos de consumo. Tudo que se deseja pode ser comprado e somente os desejos compráveis são legitimados. Sonhos que tenham direta e puramente o desejo de ser feliz com os outros são considerados ingênuos. A sociedade contemporânea nos seduz a termos somente o sonho do acúmulo como meio de aquisição de conforto.

\section{0 sonho como devaneio numa perspectiva Bachelardiana}

O devaneio poético é uma possibilidade humana em que se vive plenamente o sentido de algo que vem ao nosso encontro. Sua vivência permite que nós nos apropriemos de significados extremamente ricos e que dizem respeito ao mundo que está ao nosso redor. Por imaginação, entendemos, neste artigo, 'imaginação criadora' no sentido do termo atribuído por Bachelard, e não pelo que se costuma chamar de imaginação, segundo a referência científico-metafísica que a considera um subproduto da memória.

Vamos analisar a dimensão do sonho como devaneio e imaginação criadora a partir de um estudo sobre a imaginação poética. 0 modo como Bachelard compreende poética e imaginação nos pareceu privilegiado para apoiarmos nossas reflexões. $\mathrm{O}$ autor entende a poética como fenômeno da dimensão do imaginário humano. Por isso ele fala em imaginação poética. Um fragmento de poema para ele não é uma metáfora, pois esta teria caráter de comparação e associação de conceitos, mas é uma imagem poética. A imagem poética como ele defende, fala por si só e não demanda uma reflexão conceitual, mas uma abertura para apreender o poema, ao permitir que ele fale por nós.

0 devaneio que defendemos neste artigo, modalidade de sonho rica de significados e sentidos, só pode ser expresso poeticamente. Somente a poética, pela liberdade em falar do velho de um modo novo pode refletir esse momento. Existem até outros modos de expressar o instante do devaneio, mas o devaneio só fala poeticamente. A imagem poética tem sentido ontológico e é apreendida pelo leitor acompanhada pelo sentimento de pertencimento. "Essa imagem que a leitura do poema nos oferece torna-se realmente nossa. Enraíza-se em nós mesmos. Nós a recebemos, mas sentimos a impressão de que teríamos podido criá-la, de que deveríamos tê-la criado" (Bachelard, 2000, p. 7). A expressão poética do devaneio oferece um enraizamento da nossa intimidade, de nossa proximidade com o mundo e com os outros perdidas quando o homem se desenraiza pela técnica.

A apreensão de um poema envolve duas dinâmicas distintas, mas articuladas e complementares - de modo que podemos nos ater mais acentuadamente em uma do que em outra: repercussão e ressonância. A repercussão diz respeito ao modo como somos sensibilizados pela imagem poética; nela nos apropriamos do poema, sentindo que seus significados nos dizem respeito. A ressonância é uma elaboração intelectual posterior que dá sentido ao poema; é uma apreensão superficial que o contextualiza, e seus desdobramentos, próprios da intelectualidade "[...] dispersam-se nos diferentes planos da nossa vida no mundo" (Bachelard, 2000, p. 7) e produzem documentos psicológicos.

Bachelard ressalta que a Psicologia limita-se a estudar a ressonância poética, buscando contextualizar o poema socioculturalmente, e a partir da história de vida do poeta. $\mathrm{O}$ autor defende que falta à Psicologia um estudo a respeito da repercussão poética e volta parte de sua obra às imagens poéticas que são apreendidas em repercussão pelo leitor.

Um estudo fenomenológico sobre a imaginação e o devaneio poético é importante, pois o devaneio, por meio da vivência de repercussão de uma imagem, pode devolver o indivíduo para si mesmo e o faz apropriar-se de seu próprio mundo, libertando-o do que não lhe diz respeito.

De um modo mais geral, compreende-se também todo o interesse que há, acreditamos nós, em determinar uma fenomenologia do imaginário onde a imaginação

Psicol. Argum. 2012 abr./jun., 30(69), 307-316 
é colocada no seu lugar, como princípio de excitação direta do devir psíquico. A imaginação tenta um futuro. A princípio ela é um fator de imprudência que nos afasta das pesadas estabilidades. Veremos que certos devaneios poéticos são hipóteses de vida que alargam nossa vida dando confiança no universo [...]. Um mundo se forma no nosso devaneio, um mundo que é o nosso mundo. E esse mundo sonhado ensina-nos possibilidades de engrandecimento de nosso ser nesse universo que é o nosso (Bachelard, 1996, p. 8).

Um estudo aprofundado acerca da imaginação e o devaneio poéticos poderá tornar o psicoterapeuta suficientemente sensível para acompanhar e auxiliar seu paciente a apoderar-se de si mesmo, por meio da apropriação da sua capacidade de sonhar. A escolha da imaginação poética como referência para o sonhar e a "imaginação criadora" se deu também pelo fato de a poética ser uma via de linguagem articulada à via compreensiva, própria da proposta psicológica fenomenológica existencial. Este item pretende, a partir de uma reflexão sobre a imaginação poética de Gaston Bachelard, pensar em possíveis contribuições à psicologia clínica fenomenológica existencial, ampliando a compreensão a respeito da imaginação e o sonhar.

A imaginação poética pode servir como linguagem possível na prática psicoterápica, por oferecer imagens de rico significado humano para o psicoterapeuta e por deixá-lo mais sensível para compreender e legitimar os devaneios de seus pacientes. Estes, embora não escrevam sobre seus devaneios, tornando-os poéticos, devaneiam, por exemplo, ao lembrarem-se de sua infância e revivê-la, ou mesmo ao se entregarem a um momento contemplativo ou ao terem um insight.

No plano da proposta psicoterápica, as imagens poéticas podem servir como referências (ou guias) para o psicoterapeuta compreender o discurso do paciente. A poética é uma linguagem compreensiva e por isso pode se aproximar da linguagem enquanto poiesis proposta pela prática clínica fenomenológica existencial.

Medard Boss (1981), que desenvolve uma proposta psicoterápica de fundamentação fenomenológica existencial - chamada daseinsanalyse -, considera que as contribuições verdadeiramente importantes da perspectiva fenomenológica existencial, para a prática clínica, fundamentam-se na compreensão mais aprofundada da existência humana, e não na aplicação de técnicas psicoterápicas. Essa abordagem fundamenta-se numa perspectiva compreensiva em que a dimensão explicativa e causalista não são relevantes. Nesse sentido, as imagens poéticas, por serem do âmbito da compreensão, diferentemente dos conceitos, que são do âmbito da explicação, podem ser modalidades compreensivas significativas para um terapeuta existencial.

Na terapia, o que fazemos é reencontrar a expressão do nosso modo de sentir, o recordado, principalmente daquelas coisas que já nos foram caras, que já foram coisas do coração, mas que perderam esse vínculo em função de dificuldades de comunicação, tornando-se desgastadas. Foram esquecidas, mas num esforço de procura por meio da linguagem poética (grifo do autor), podemos reencontrá-las. Quando isto acontece, encontramos uma verdade (Pompéia \& Sapienza, 2004, p. 161).

As verdades encontradas durante a procura psicoterapêutica, que se dá por meio da linguagem poética, são compreensões libertadoras. 0 paciente esclarece e conta com novas possibilidades de ser e pode, a partir delas, fazer suas escolhas de modo mais apropriado. A libertação do paciente para suas próprias possibilidades de ser é o que a psicoterapia deseinsanalítica se propõe.

Se a prática psicoterápica se orientar num relacionamento fenomenológico com o mundo, então ela pode recuperar sua própria natureza e essência. Sua essência consiste no fato dela mesma ser livre e de permitir aos homens serem livres dentro dela. Como psicoterapeutas queremos, no fundo, libertar nossos pacientes para si mesmos [...]. Por isso, com a libertação psicoterápica, queremos levar nossos pacientes 'apenas' a aceitar suas possibilidades de vida como próprias e a dispor delas livremente e com responsabilidade. Isto quer dizer também, que nós queremos que eles criem coragem de levar a termo suas possibilidades de relacionamento co-humanos e sociais de acordo com sua consciência intrínseca e não como uma pseudo-consciência imposta por qualquer um (Boss, 1981, p. 61).

Retomando Bachelard, acreditamos que a imaginação poética possa ser um modo de relacionamento com nossa intimidade que nos traz para perto de nós, que faz florescer o que é nosso, o nosso modo de darmos sentido e significarmos nossas vidas. Assim sendo, a imaginação poética pode ajudar as pessoas a se apropriarem de suas próprias possibilidades e 
não se guiarem por imposições alheias a nós, como aponta Boss na afirmação anterior.

Um dos encantos da fenomenologia da imaginação poética é poder viver numa nuança nova diante de um espetáculo que convida à uniformidade, que se resume numa ideia. Se a nuança é sinceramente vivida pelo poeta, o fenomenólogo está certo de captar um ponto de partida de uma imagem (Bachelard, 2000, p. 208).

Bachelard valoriza a singularidade e a riqueza de um modo próprio e original de se falar de algo do mundo, proporcionado pela imaginação poética. Quando uma imagem poética, nos toca, compartilhamos com o mundo de uma intimidade, damos sentido e significamos nossas vidas. Quando uma imagem poética nos toca, ela nos faz sentir mais próximos dos outros. Percebemos que os nossos sentimentos pertencem a nós e ao mundo; pertencemos ao mundo porque este, por meio da imagem poética, dá expressão ao que sentimos estando no mundo.

Em uma imagem poética de D'Annunzio, trazida por Bachelard, o poeta fala da paz dos campos no olhar de uma lebre que sai pela manhã, para e olha para o horizonte. Segundo Bachelard, os "espíritos apoéticos" poderiam objetar o fato de o poeta utilizar o olhar da lebre para falar da paz dos campos, ao invés de falar dessa paz diretamente. 0 poeta fala aqui de contemplação, de um olhar que contempla e não um olhar que vê um objeto específico. Fala de uma integração da paz animal à paz do mundo. Assim, "por um instante o animal dannunziano é liberado de seus reflexos; [...] realmente tal olhar no animal do medo, é o instante sagrado da contemplação" (Bachelard, 2000, p. 113). Para podermos seguir a imagem poética, é preciso um modo de ser no mundo, diferente do qual estamos acostumados, racionalista, que olha de longe, mede e calcula. É preciso um modo contemplativo, estarmos contemplativamente no mundo.

Ao trabalhar imagens poéticas de ninho, Bachelard não o fará sob o conceito de ambiente natural da Biologia, mas tratará de um ninho sonhado, de imagens que eles nos suscita em nossos devaneios. Na seguinte imagem de Adolphe Shedrow (apud Bachelard, 2000, p. 116) "Sonhei com um ninho em que as árvores repeliam a morte", o ninho é visto sob o caráter de confiança no mundo de uma "segurança cósmica". Mesmo com grande precariedade e vulnerabilidade, o ninho nos dá segurança porque confiamos no mundo. Para Bachelard, a vida começa, a partir dos sonhos, com "um sono tranquilo". A hostilidade do mundo é posterior, assim como sonhos de agressividade e defesa. "Em seu germe, toda a vida é bem-estar. 0 ser começa pelo bem-estar. Em sua contemplação do ninho, o filósofo tranquiliza-se seguindo uma meditação de seu ser no ser tranquilo do mundo" (Bachelard, 2000, p. 116).

Na clínica psicoterápica, poderíamos facilitar nossos pacientes a se expressarem poeticamente. Com isso não estamos entendendo que o terapeuta condicione a expressão do paciente à elaboração de um poema, em que o terapeuta de certo modo o capacitaria. Estamos falando em ajudar os pacientes a encontrarem um contato consigo, cuja expressão é eminentemente poética. Um contato íntimo que um modo de dizer poético (claro que não um poema formalizado) pode expressá-lo. A poética também poderia ser um modo do terapeuta compreender falas do paciente que dizem respeito ao seu mundo imaginário.

\section{Considerações finais}

\section{Como a clínica poderia resgatar a capacidade de sonhar?}

Ambas as modalidades de sonho que abordamos são modos íntimos do ser humano lidar consigo e com o mundo ao seu redor. Essa relação de intimidade, conforme defendemos, é que perdemos a partir de vivermos em função da técnica. 0 desenraizamento que apontamos fala justamente de uma falta de intimidade que temos adquirido em relação às pessoas, aos lugares e a nós. Assim, um olhar para o sonho, com o sentido de lhe dar uma atenção especial em psicoterapia, é o que desejamos apontar com este artigo.

Na prática clínica, nós, terapeutas, podemos estar mais atentos ao modo como nossos pacientes vivem a dimensão do sonho. Acreditamos que, como modo de nos encontrarmos, de apropriarmos do nosso modo próprio de ser, modalidades de sonho como a imaginação poética e a vivência de um desejo até a sua morte e o nascimento de outro desejo sonhado podem ajudar o paciente. Assim, o desejar do sonhador é um modo próprio de relacionar-se com algum fenômeno, aponta para o modo como é tocado por algo ou alguém e expressa seu modo de ser-no-mundo humano, aberto aos fenômenos que encontra.

Considerando tal contexto, este artigo procurou mostrar que um olhar mais aprofundado para a 
dimensão do sonho é uma forma de recuperar um lugar ocupado na existência humana que não tem utilidade teórico-prática na perspectiva da técnica e, por isso, tem sido relegado pela nossa sociedade capitalista contemporânea.

Algo do sofrimento típico da nossa sociedade contemporânea poderia ser a expressão do nosso afastamento da nossa capacidade de sonhar? Não procuramos responder a essa questão com uma resposta na forma de uma explicação causal, indutiva ou dedutiva, mas procuramos refletir a respeito da questão e abri-la para novas discussões. Entendemos, como procuramos mostrar ao longo do artigo, que o sonho tem relação estreita com nossa intimidade, com nosso modo de estar no mundo, e, por isso, nos pareceu relevante ampliarmos nossas reflexões acerca dele numa época em que a sociedade privilegia e incentiva padrões de ser, que se enquadrem nas dinâmicas da produção, do consumo e do poder. A intimidade, comprometida por estar sem lugar no mundo da técnica, pode ser melhor compreendida a partir de uma reflexão sobre nossa capacidade de sonhar.

Todos somos tocados de um modo muito pessoal e íntimo por nossos sonhos, que nos convidam a viver uma determinada experiência ou de uma determinada maneira. Nossa sociedade não reconhece importância na maioria de nossos sonhos. A realização da técnica só é possível sem a consideração e apropriação dos sonhos íntimos. Ela se faz com projetos racionalmente estabelecidos de controle, produção, consumo e poder. Muitas pessoas deixam de viver seus sonhos porque cedem ao forte apelo da sociedade para serem de forma padronizada. Reencontrar a importância de nossos sonhos para nós, procurar uma forma de compartilhá-lo com o mundo e aprender a deixá-los morrer quando eles não tiverem mais lugar no mundo, abrindo espaço para que outro sonho nos toque, parece-nos, portanto, importante e pertinente à proposta da prática clínica psicológica fenomenológica existencial, que é a de libertar o paciente para suas próprias possibilidades de ser.

\section{Referências}

Aristóteles. (1969). Metafísica. Porto Alegre: Globo.

Bachelard, G. (1996). A poética do devaneio. São Paulo: M. Fontes.

Bachelard, G. (2000). A poética do espaço. São Paulo: M. Fontes

Bachelard, G. (2001). A terra e os devaneios da vontade. São Paulo: M. Fontes.

Boss, M. (1981). Angústia, culpa e libertação (ensaios de psicanálise existencial). São Paulo: Livraria Duas Cidades.

Critelli, D. M. (1996). Analítica do sentido. São Paulo: EDUC - Brasiliense.

Descartes, R. (2008). Discurso do método. Porto Alegre: L\&PM Pocket.

Heidegger, M. (2001). Seminários de Zollikon. São Paulo: EDUC; Petrópolis: Vozes.

Heidegger, M. (2008). Ser e tempo. Petrópolis: Vozes.

Heráclito (1999). Heráclito de Éfeso. São Paulo: Nova Cultural.

Michelazzo, J. C. (2000). Perspectivas do novo paradigma em Heidegger: Superar a metafísica, resgatar a metafísica e salvaguardar o homem. In D. S. P. Castro, D. D. Pokladek, F. P. Ázar, J. D. Piccino \& R. S. Josgrilberg (Org.). Existência e saúde (pp. 119-148). São Bernardo do Campo: UMESP-FENPEC.

Michelazzo, J. C. (2003). Corpo e tempo. In D. S. P. Castro, R. S. Josgrilberg, T. A. Goto \& J. D. Piccino (Org.). Corpo e existência (pp. 105-122). São Bernardo do Campo: UMESP-FENPEC.

Platão. (1999). A República. São Paulo: Nova Cultural.

Pompéia, J. A., \& Sapienza, B. T. (2004). Na presença do sentido. São Paulo: Paulus. 